\title{
CIPP 评价模式在创新创业教育质量评价中的应用
}

\section{The Application of CIPP Evaluation Model in Quality Evaluation of Innovation and Entrepreneurship Education \\ 李书霞}

Shuxia $\mathrm{Li}$

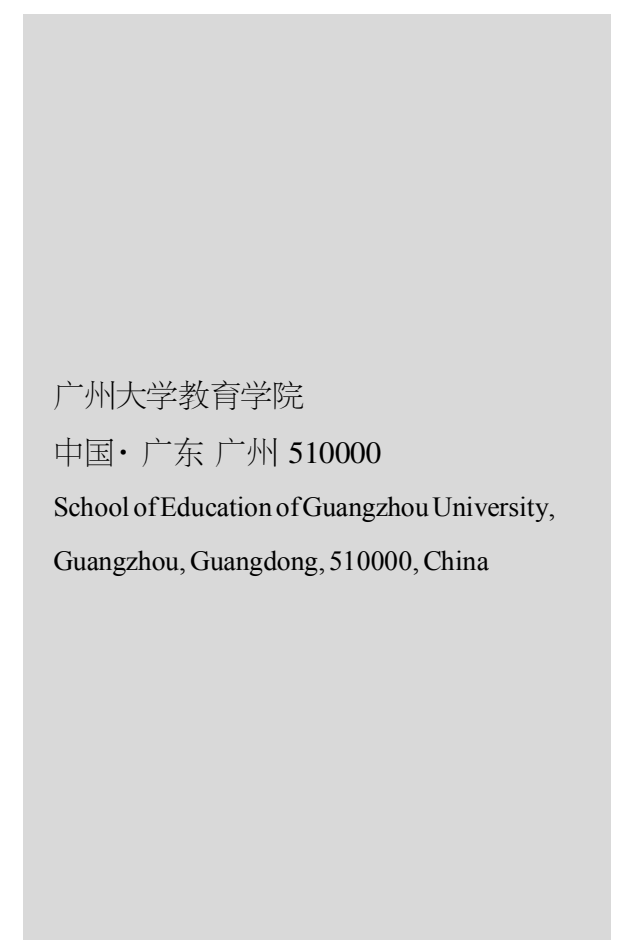

\section{1 问题的提出}

近年来，中华人民共和国国务院办公厅和教育部出台了 一系列创新创业教育相关政策文件，国家层面的系统设计和 全面部署极大地促进了中国高校创新创业教育的发展[1]。纵观 中国高校创新创业教育质量评价体系的相关研究，有两个问 题尤为突出:一是过于关注高校创新创业教育的成果和绩效, 过分依赖“创业率”,对其活动过程和改进工作的重视不够;二 是缺乏相关的理论基础,评价指标体系的主观化倾向较突出, 导致指标松散、关联性弱、逻辑性和统一性不强[2]。如何科学、 客观、全面地评价高校创新创业教育质量, 已成为中国创新创 业教育面临的重要问题之一。

\section{Cipp 评价模式的内涵}

评价模式代表教育评价理论的观点和流派，是在教育 评价的发展过程中逐渐形成的，每种评价模式都具有其独 特的使用价值 ${ }^{[3]}$ 。主要的评价模式包括行为目标模式、CIPP 模式、目标游离模式、应答模式等, 其中理论和步骤较完整、
影响较大的,当数 CIPP 模式。CIPP 是四类评价的英文缩写: 背景评价 (context evaluation)、输入评价 (input evaluation)、 过程评价 (process evaluation)、成果评价(product evaluation), 这四类评价既是内容也是步骤, 有机组合共同构成了 CIPP 模式。

\section{1 背景评价}

对教育方案目标自身进行的合理性评价。通过鉴别需求、 问题、有利条件和机会, 为选择和形成方案目标提供依据和提 供有效信息, 关注确定与描述方案目标以及对方案目标的合 理性的判断。背景评价服务于计划决策, 本质上是依据社会发 展和评价对象的需要对方案目标作出的诊断性评价。

\section{2 输入评价}

对教育方案所需条件进行的可行性评价。通过评价实现 目标所需条件、资源以及各备选方案和可能获得条件, 判断教 育方案的优劣, 关注评价目标需要的资源配置和投入情况, 以 评价目标设定是否 ${ }^{[4]}$ 。输人评价服务于组织决策, 本质上是对 方案的效用性和可行性评价。 


\section{3 过程评价}

对教育方案实施情况进行的形成性评价。通过监控、记录 和反馈所选方案的实施过程, 对实践活动和成效开展跟踪分 析, 并不断调整和改进实施过程。CIPP 模式与目标模式的最 大区别就是过程评价, 强调过程评价的重要作用, 在过程中发 现问题以不断调整和改进。过程评价服务于实施决策, 本质上 是对教育方案实施状况的督导与反馈的形成性评价 ${ }^{[5]}$ 。

\section{4 成果评价}

对教育方案实施结果进行的终结性评价。通过测量、判 断、解释方案的成就, 评价目标达到的程度, 确定人们的需要 满足的程度,并检视方案成果与设定目标之间的差异情况。成 果评价是对结果予以评价, 及时反馈和改进方案实施, 它通过 衡量、分析方案实施成果, 以此为依据决定是否继续使用、修 正或终止方案。成果评价服务于再循环决策, 本质上是对教育 方案的终结性评价。

3 CIPP 评价模式对创新创业教育质量评 价的适切性分析

\subsection{CIPP 模式的理念契合了创新创业教育质量 评价的目的}

“评价的关键不在于证明，而在于改进”(not to prove but to improve), CIPP 模式四类评价关注重点不同, 但都环绕着这 个核心价值理念, 它认为评价就是为管理者做决策提供信息 服务的过程,为决策的各个方面提供信息, 以便更好地为教育 服务, 因而 CIPP 模式也称为决策导向或改良导向评价模式问。 对创新创业教育质量评价而言，评价是改进、提高创新创业教 育质量的基础, 评价目的在于通过及时反馈评价结果, 进一步 改进创新创业教育质量。

\subsection{CIPP 模式的框架涵括了创新创业教育质量}

\section{评价的内容}

CIPP 模式由背景评价、输入评价、过程评价、成果评价组 成,涵括了高校发展目标的评价、高校规划方案的评价、方案 实施过程的评价、高校发展成果的评价[1。四类评价关注内容 各有不同, 背景评价指向高校发展目标, 为创新创业教育实施 奠定基础; 输入评价指向教育方案组织, 为创新创业教育实施 做好准备; 过程评价指向教育实施的过程,为创新创业教育质 量做好监控; 结果评价指向教育的最终结果, 为创新创业教育 质量做好检验。

\subsection{CIPP 模式的特点适应了创新创业教育质量}

\section{评价的需要}

CIPP 模式的主要特点有：一是强调教育评价的决策功
能,整合计划、组织、实施和结果四个步骤以及再循环决策的 四个方面, 相应的形成背景、输人、过程和成果评价, 为决策者 提供改进教育服务的有价值信息; 二是该模式注重过程评价 与改进评价, 突出反馈的重要作用; 三是把诊断性评价、形成 性评价、终结性评价三种评价类型有机结合起来,科学性、系 统性、逻辑性较强 ${ }^{[8]}$ 。创新创业教育质量评价的实施有三个难 点:一是影响因素多元性,影响创新创业教育质量的因素有很 多, 诸如生源质量、成长过程、师资条件、课程教学等, 要求质 量评价体系多层级、多指标、多维度;二是过程持续性，高校创 新创业教育无法一蹴而就, 它是一个持续改进的过程, 要求不 断监测与控制创新创业教育过程和运行结果，形成有效反馈 以持续完善和优化; 三是结果时滞性, 从接受创新创业教育, 到创新创业的实践之间, 存在较长的时间延滞, 要求必须兼顾 短期效果和长期效果 ${ }^{[19}$

\section{CIPP 评价模式在创新创业教育质量评} 价中的应用

\section{1 基于“背景 C”的教育背景评价}

教育背景评价是创新创业教育质量评价的基础，它反映 了教育实施的目标和评价需要之间的匹配度。教育背景评价 是对创新创业教育目标进行诊断性评价, 聚焦于高校创新创业 教育目标的合理性评价, 关注需求、问题、有利条件和机会 ${ }^{[10]}$ 。 因此,教育背景评价选取顶层设计、知识基础和技术基础三个 分指标，顶层设计指标是高校创新创业教育需求和目的的体 现，知识基础和和技术基础指标是高校创新创业教育条件和 机会的体现。

\section{2 基于“输入 I”的资源配置评价}

资源配置评价是高校创新创业教育质量评价的重点, 它 反映了高校对创新创业教育的重视程度，也是评估创新创业 教育质量的重要影响因素。资源配置评价是对高校创新创业 教育质量提升方案科学性的评析与研判, 聚焦于高校创新创 业教育的可行性评价，关注高校创新创业教育的资源投入与 组织支持。因此，高校创新创业资源投入选取师资投入、经费 投入、设施投入和管理投入四个分指标, 这四个指标涵括了一 般意义上投入维度的人、财、物、制度四个方面。

\section{3 基于“过程 I”的教育过程评价}

教育过程评价是高校创新创业教育质量评价的关键, 它 反映了教育方案从目标、投入转化成果的活动过程, 是对高 校行动力和执行力的鉴定,看其是否有效利用资源开展活动 来推进创新创业教育。教育过程评价是对高校创新创业教育 实施情况进行的形成性评价, 聚焦于高校创新创业教育过程 
理论实践 Theoretical Practice

的动态性与反馈性, 关注创新创业教育方案的执行情况。

\section{4 基于“成果 $P ”$ 的成果绩效评价}

成果绩效评价是创新创业教育质量评价的落脚点, 它反 映了学生创新创业能力和高校创新创业教育成效的高低, 是 衡量教育质量和水平最直接的指标。成果绩效评价是对高校 创新创业教育活动实际结果的终结性评价，聚焦于创新创业 教育方案实施的成果, 关注成果的反馈信息的获得, 为创新创 业教育的改进提供直接的依据。因而,成果绩效评价分别从学 生、高校、社会三个角度选取素养提升、创新创业效果和社会 效益三个分指标，以不同角度展现高校创新创业教育的影响 和成就。

\section{参考文献}

[1]康建军,季仕锋,王道峰.基于大创业教育观的质量评价:理念、 逻辑与维度 $[J]$.教育与职业,2019(10):56-62.

[2]孙鹏,黄福华.基于 CIPP 的应用型本科院校创新创业教育质
量评价模型构建 $[\mathrm{J}]$.物流工程与管理,2018,40(5):175-177.

[3]高振强.CIPP 教育评价模式述评[J].教学与管理,1998(Z1):57-59.

[4]王盈,李平.CIPP 模式在高校文化素质教育课程评价中的应用 [J].宁波大学学报(教育科学版),2009,31(3):1-6.

[5] 朱丹.CIPP 评价模式在综合实践活动课程评价中的运用 [J]. 基础教育研究,2010(1):18-19+22.

[6]钟之静.基于产教融合视阈构建高校创新创业教育评价体系 [J].广东技术师范学院学报,2019,40(4):20-25.

[7]王占仁,刘志,刘海滨, 等.创新创业教育评价的现状、问题与趋 势[J].思想理论教育,2016(8):89-94+103.

[8]蒋国勇.基于 CIPP 的高等教育评价的理论与实践 [J].中国高 教研究,2007(8):10-12.

[9]肖远军.CIPP 教育评价模式探析[J].教育科学,2003(3):42-45.

[10]王兴立. 大学生创新创业教育质量评价的矛盾困境、体系优 化及创新举措[J].教育与职业,2018(4):68-72.

\section{(上接第 121 页)}

型、实验室等,增加学生的参与力度。桥遂产品一般有波纹管 针固系统以及钢角线等, 让学生能够对基本的桥隧产品有更 明确的认识, 还需要理解桥遂的设备, 包括相应的模板, 脚手 架以及钢筋类的设备等, 让学生能够更好地去对桥隧的模型 产品设备进行了解, 为有效地进行实习实训学习, 打下良好的 基础。

\section{5 合理采用案例教学}

高职院校桥遂专业类课程的实习实训环节至关重要,需 要不断地加强实践,完善好实践的教学课程,创新教学模式, 通过专业的施工方案，案例将施工中有关的基础知识与施工 技能方法联合起来，制定好详细的施工方案，根据实际的情 况, 再加以调整。

\section{6 竞赛模式}

通过桥遂模型竞赛,提高学生的积极性,高职院校应该定 期的举行模型竞赛,在这一过程中,可以提高学生的创造性思 维, 激发学生的学习兴趣, 强化学生在实习实训环节中的团结 能力, 使学生能够更好地掌握施工的原理, 以及施工技术、施 工构造等。

\section{7 完善教学模式}

高职院校在桥遂专业教学过程中，应该不断完善教学模 式,创新教学方式, 培养学生的实践能力 ${ }^{[3]}$ 。要想在有效的时 间内加强学生的实践能力, 就应该多做实验, 激发学生的学习
兴趣, 在实验的过程中, 选择难度较小的, 比如钢筋骨架绑扎, 预应力模拟实验以及混凝土强度的检测等, 只有学生掌握了 最基础的实验, 才能够由浅入深, 更深入地学习桥遂实训。

\section{8 明确顶岗实习管理和指导的重点}

在实习实训环节中, 需要加强顶岗学习管理和指导, 能够 更好地锻炼学生的自信心, 考验学生的承受能力更好地为以 后学生在工作中能够快速的适应环境, 提高学生的抗压能力, 打下良好的基础。

\section{3 结语}

随着课程改革的不断发展, 实习实训环节也应与工程实 践紧密相连, 更好地满足企业发展的需求, 学生通过动画录 像, 竞赛案例等实训方式进行感受, 实践以及思考等, 提高学 生的理解能力, 合理安排知识的难易程度, 以实训报告的方式 锻炼学生的能力, 对于存在的问题, 应该积极采取相应的措施 调动教师的积极性, 促进桥隧类课程的实习实训环节良好的 开展。

\section{参考文献}

[1]吴林松.高速公路桥隧工程关键工序施工安全风险致因分析 [J].企业技术开发,2019(7):20-25.

[2]刘明利.隧道工程施工中难点及改进措施[J].黑龙江交通科技, 2018(9):171-172.

[3]潘军宁,辛文杰,何杰,等.河口海岸桥隧工程设计流速推算[J]. 水科学进展,2019(6):845-853. 